\title{
Escala de Crenças sobre a "Cura" da Homossexualidade [ECCH]: desenvolvimento e evidências psicométricas
}

\author{
Escala de creencias sobre la "Cura" de la homosexualidad (Ecch): desarrollo y \\ evidencias psicométricas

\section{Scale of Beliefs on the "Cure" of Homosexuality [EcCH): Development and Psychometric Euidences}

\author{
Alessandro Teixeira Rezende \\ Valdiney Veloso Gouveia \\ Heloísa Bárbara Cunha Moizéis \\ Francicléia Lopes Silva \\ Jéssyca Cristina Freitas Nunes \\ Universidade Federal da Paraíba
}

Doi: https://doi.org/10.12804/revistas.urosario.edu.co/apl/a.8438

\section{Resumo}

O presente estudo teve como objetivo desenvolver a Escala de Crenças sobre a Cura da Homossexualidade (ECCH), reunindo evidências de validade fatorial, discriminante e convergente, bem como sua consistência interna. Para tal, realizou-se um estudo com 225 estudantes universitários $\left(\mathrm{M}_{\text {idade }}=21,3\right.$ e $D P=5,78$, variando entre 18 a 59 anos; $68.5 \%$ do sexo feminino). Estes responderam a ECCH, Escala de Crenças sobre Homossexualidade (ECH), Escala de Desejabilidade
Social (EDSMC) e perguntas demográficas. Uma análise de componentes principais permitiu identificar uma estrutura com cinco componentes: crenças religiosas ( $\alpha=0.95)$, crenças morais $(\alpha=0.95)$, crenças biológicas $(\alpha=0.96)$, crenças desfavoráveis à reversão sexual $(\alpha=0.93)$ e crenças psicológicas $(\alpha=0.92)$. Corroborando evidências de validade convergente e discriminante, as dimensões da ECCH apresentaram correlações na direção esperada com as medidas de ECH e EDSMC. Conclui-se que a versão final da ECCH, formada por 20 itens, apre-

\footnotetext{
Alessandro Teixeira Rezende ORCID ID: https://orcid.org/0000-0002-5381-2155

Valdiney Veloso Gouveia ORCID ID: https://orcid.org/0000-0003-2107-5848

Heloísa Bárbara Cunha Moizéis ORCID ID: https://orcid.org/0000-0003-0477-8410

Francicléia Lopes Silva ORCID ID: https://orcid.org/0000-0002-1967-2830

Jéssyca Cristina Freitas Nunes ORCID ID: https://orcid.org/0000-0002-5703-8347

Dirigir correspondência à Alessandro Teixeira Rezende. Cidade Universitária, s/n Campus I - Castelo Branco III, João Pessoa - PB. Correio eletrônico: als_tx29@hotmail.com

Agradecemos ao financiamento do Conselho Nacional de Pesquisa (CNP) a qual permitiu o desenvolvimento da presente pesquisa.
}

Para citar este artigo: Rezende, A. T., Gouveia, V. V., Moizéis, H. B. C., Silva, F. L., \& Nunes, J. C. F. (2021). Escala de Crenças sobre a "Cura" da Homossexualidade (ECCH): desenvolvimento e evidências psicométricas. Avances en Psicología Latinoamericana, 39(1), 1-19. https://doi.org/10.12804/revistas.urosario.edu.co/ap1/a.8438 
senta evidências psicométricas adequadas para avaliar crenças sobre a cura da homossexualidade, podendo ser utilizada em pesquisas no contexto brasileiro, permitindo conhecer seus possíveis correlatos.

Palavras-chave: crenças; cura; homossexualidade; validade; precisão.

\section{fibstract}

The present study aimed to develop the Belief on the Cure of Homosexuality Scale (BCHS), gathering evidence of factorial, discriminant, and convergent validity, as well as its internal consistency. For this, a study was conducted with 225 university students (mean age $=21.3$ and $\mathrm{SD}=5.78$, ranging from 18 to 59 years; $68.5 \%$ female), who answered the BCHS, the Beliefs about Homosexuality Scale (BHS), Social Desirability Scale (MC-SDS), and demographic questions. An analysis of the principal components allowed to identify a structure with five components: religious beliefs $(\alpha=0.95)$, moral beliefs $(\alpha=0.95)$, biological beliefs $(\alpha=0.96)$, beliefs unfavor able to sexual reversion $(\alpha=0.93)$, and psychological beliefs $(\alpha=0.92)$. Corroborating evidence of convergent and discriminant validity, the BCHS dimensions correlated in the expected direction with the BHS and MC-SDS measures. Results allowed concluding that the final version of the BCHS, consisting of 20 items, presents adequate psychometric evidence to evaluate beliefs about the cure of homosexuality and can be used in research in the Brazilian context, allowing to know its possible correlates.

Keywords: Beliefs; cure; homosexuality; validity; precision.

\section{Resumen}

Este estudio tuvo como objetivo desarrollar la Escala de Creencias sobre la Cura de la Homosexualidad (ECCH), reuniendo evidencia de validez factorial, discriminante y convergente, así como su consistencia interna. Para ello, se realizó un estudio con 225 estudiantes universitarios (media de edad $=21.3$ y $D P=5.78$, rango de 18 a 59 años; $68.5 \%$ mujeres). Estos respondieron la ECCH, la Escala de Creencias sobre Homosexualidad (ECH), la Escala de Deseabilidad Social (EDSMC) y preguntas demográficas. Un análisis de componentes principales permitió identificar una estructura con cinco componentes: creencias religiosas $(\alpha=0.95)$, creencias morales $(\alpha=0.95)$, creencias biológicas $(\alpha=0.96)$, creencias desfavorables a la reversión sexual $(\alpha=0.93)$ y creencias psicológicas $(\alpha=0.92)$. Corroborando la evidencia de validez convergente y discriminante, las dimensiones de la $\mathrm{ECCH}$ mostraron correlaciones en la dirección esperada con las medidas de ECH y EDSMC. Se concluye que la versión final de la $\mathrm{ECCH}$, formada por 20 ítems, presenta evidencia psicométrica adecuada para evaluar creencias sobre la cura de la homosexualidad, la cual puede ser utilizada en investigaciones en el contexto brasileño, permitiendo conocer sus posibles correlatos.

Palabras clave: creencias; cura; homosexualidad; validez; precisión.

Em meados de 1985, o Conselho Federal de Medicina removeu a homossexualidade do manual de diagnóstico de perturbações mentais. $\mathrm{O}$ conselho Federal de Psicologia, por sua vez, promulgou em 1999 a resolução 01/99, que estabelece que a homossexualidade não poderia ser mais considerada uma doença, distúrbio e perversão, ficando o psicólogo impedido de colaborar com propostas de tratamentos voltados para a cura da homossexualidade (Mesquita, 2018).

Em face deste contexto, as principais organizações vinculadas a saúde não consideram mais a homossexualidade como uma patologia, mas sim como uma das possibilidades de expressão afetiva e sexual. Dessa forma, é possível constatar regulamentações e diretrizes (e.g., American Psychological Association e Conselho Federal de Psicologia) que advogam uma atuação psicológica que não patologize a homossexualidade (Sposito, 2015).

Com o estabelecimento dessas resoluções, o foco de estudo da Psicologia deixou de ser a homossexualidade enquanto patologia, passando a dar ênfase no contexto de vida das pessoas homossexuais e ao 
preconceito do qual esse público é vítima (Whitley $\&$ Kite, 2016). A partir dessa mudança de foco, o tema da homossexualidade passou a ser alvo de um forte debate social, tanto à nível da igualdade de direitos humanos (e.g., casamento civil e adoção de filhos por casais homoafetivos), quanto no combate à discriminação contra esse grupo (Herek, 2015).

Todavia, mesmo diante desse cenário de avanço, diversos profissionais da Psicologia e políticos cristãos passaram a reivindicar o retorno da Psicologia a uma atuação voltada para a "cura da homossexualidade", através de projetos de leis que pretendiam sustar a regulação 001/99. Nessa oportunidade, cita-se a decisão liminar da Justiça Federal do Distrito Federal que acatou parcialmente uma ação popular contra a Resolução 001/99. Tal decisão abriria a possibilidade de atuar nas questões relativas à reorientação sexual (CFP, 2017). Não obstante, o Supremo Tribunal Federal (STF) em abril de 2019 concedeu liminar ao Conselho Federal de Psicologia, mantendo na íntegra a resolução que determina que não cabe aos profissionais da Psicologia o oferecimento de qualquer tipo de prática de reversão sexual, tendo em vista que a homossexualidade não é uma patologia, doença ou desvio (CFP, 2019).

Macedo e Sívori (2019) ao discutirem sobre a diversidade sexual na Psicologia brasileira postulam que as chamadas "terapias de reorientação sexual" representam um desafio para o desenvolvimento científico e profissional da Psicologia, bem como para o exercício e livre expressão da orientação sexual como um direito humano. Para além de descredibilizar a Psicologia como uma área científica, as controvérsias criadas pela posição do Conselho Federal de Psicologia (CFP) em relação a homossexualidade e religião ultrapassam o domínio da Psicologia e da sua regulamentação como profissão, para se tornar mais uma disputa sobre uma política sexual no Brasil. Pensar o retorno das terapias de reversão sexual como um problema que vai para além da regulamentação da profissão, mas que implica também em questões políticas e ideológicas é compreender que a defesa da reorientação sexual está alicerçada em uma lógica de naturalização da heterossexualidade como único padrão "normal" a ser seguido, visando garantir assim uma estrutura social que diminua consideravelmente o espaço de cidadania e direitos para pessoas que vivenciam as mais diversas expressões de gênero e orientação sexual (Cassal et al., 2019; Macedo, 2017; Macedo \& Sívori, 2018).

Assumir a perspectiva de que a homossexualidade tem cura, implica em colocar a comunidade LGBT em uma condição de desviante, ou seja, de pessoas que precisam se readequar a um estado considerado "normal" ou "convencional" (Sousa, 2017). Dentro dessa discussão, Costa et al. (2018) pontuam que ao longo da história, os motivos que levavam os homossexuais a procurarem serviços de reorientação sexual, não estavam ligados à sua orientação sexual de fato, mas, às contigências aversivas (e.g., preconceito, agressão, exclusão) que estes eram expostos por não serem heterossexuais. Em meio a isso, estudos (e.g., Bartlett et al., 2009; Smith et al., 2004) mostraram que a tendência de buscar tratamento para reorientação sexual era alta, pois o problema residia no ambiente externo (e.g., intolerância, discriminação) e não na atração pelo mesmo sexo.

A partir dessa constatação, as pesquisas realizadas na área começaram a verificar que muitas das noções que foram tomadas para incluir a homossexualidade como doença e transtorno não faziam uso de procedimentos adequados, tais como a utilização de amostras representativas da população homossexual (Toro-Alfonso, 2005). Nesta direção, no início dos anos 1970, começaram a ser realizadas pesquisas que mostraram evidências de que os homossexuais não eram psicologicamente diferentes dos heterossexuais (Kinsey et al., 1948).

Um dos maiores precursores nessa área foi Hooker (1956) que fez uma comparação entre um grupo de homens heterossexuais e homossexuais em termos de seu desempenho em vários 
testes psicológicos padronizados, como o teste de Roshchach e de percepção temática. Os resultados indicaram que não foi possível determinar a orientação sexual por meio dos testes psicológicos, o que levou o autor a concluir que a homossexualidade não existia como entidade clínica, ou seja, não era uma patologia ou doença mental.

Face a esse panorama, pode-se afirmar que os desafios relacionados à homossexualidade no contexto atual são baseados principalmente em questões morais, religiosas e políticas, e não em razões médicas ou clínicas. No entanto, na maior parte da população ainda permeia uma noção da homossexualidade como algo imoral, pecaminoso e patológico (Pereira, 2017). Paralela a essa discussão, Fleury e Torres (2010) destacam que a concepção da homossexualidade como pecado provém da perspectiva de que a relação sexual entre duas pessoas do mesmo sexo é tida como moralmente errada e pecaminosa. Já a homossexualidade como doença, compreende a prática sexual entre duas pessoas como uma patologia que acomete os indivíduos e os coloca em contraposição à uma condição normal e saudável.

Apesar de atualmente, coexistirem práticas de retrocessos encampadas pela própria Psicologia que violam direitos humanos das minorias sexuais, foi da Psicologia, uma das maiores contribuições para o estudo dessa temática. Especificamente no âmbito da Psicologia Social, estudos evidenciam que a discriminação e o preconceito contra homossexuais se embasam em um sistema de representações que envolvem crenças preconceituosas acerca da natureza da homossexualidade, sendo as mesmas historicamente construídas e compartilhadas entre os indivíduos (Pereira et al., 2016; Pereira et al., 2014).

Nessa direção, as crenças estariam na base da expressão de atitudes e comportamentos preconceituosos. Rokeach (1973), por exemplo, define as crenças como percepções específicas de atributos de objetos e fenômenos pessoais e sociais, retratando comportamentos ou situações específicas. Dessa forma, as crenças podem ser estritamente pessoais, quando expressam, por exemplo, uma avaliação ou julgamento a respeito de alguém, mas também podem ser compartilhadas, como nos casos das opiniões socialmente disseminadas sobre as causas e natureza da homossexualidade.

Paralela a essa discussão, Lacerda et al. (2002) identificaram cinco princípios organizadores das crenças sobre a homossexualidade, a saber: as crenças religiosas que situam o homossexual como uma pessoa que não segue a palavra de Deus e que não tem força espiritual e fé para resistir as tentações da "carne"; as crenças ético-morais que caracterizam a homossexualidade como ausência de respeito, de caráter e de valores morais; as crenças psicológicas que representam a homossexualidade como uma doença de base psicológica relacionada a alguma situação traumática vivida na infância; as crenças biológicas que se baseiam na ideia de que a homossexualidade seria uma doença provocada por distúrbios de natureza fisiológica, hormonal ou gestacional; e por fim, as crenças psicossociais que estariam ancoradas na ideia de que a homossexualidade não é doença e deve ser compreendida na sua totalidade como uma forma de expressão de identidade do sujeito.

Mediante o exposto, torna-se perceptível que algumas concepções acerca da natureza da homossexualidade têm proposto que as teorias científicas (tanto biológicas como psicológicas) e religiosas têm servido de base para a construção de estigmas em relação aos homossexuais, contribuindo para legitimar a adoção de comportamentos discriminatórios (Pereira et al., 2016). Em outras palavras, tais crenças contribuem para manutenção de uma imagem fixa e imutável dos homossexuais, na medida que salientam uma representação essencialista do homossexual como portador de alguma anormalidade biológica ou psicológica, que o impulsiona à violação dos valores tradicionais que sustentam o status quo (Gato \& Fontaine, 2016).

O estigma social da homossexualidade ou qualquer outra forma de orientação sexual que fuja dos padrões heteronormativos, refere-se à crença 
compartilhada de que a homossexualidade é condenável e socialmente reprovável, devendo a mesma ser submetida a tratamentos ou terapias voltadas para sua "cura". A origem dessas concepções não interfere apenas no modo como o alvo é tratado, mas como o portador, visualiza a si próprio por causa desse estigma (Pachankis et al., 2015). A esse respeito, estudos apontam que lésbicas, gays, bissexuais e transexuais (LGBT) apresentam níveis mais altos de depressão, ansiedade, abuso de substâncias e suicídio quando comparados aos heterossexuais (Pakula et al., 2016; Smith et al., 2016), indicando que um ambiente social hostil parece promover efeitos negativos na saúde mental de membros de grupos marginalizados.

Tendo em vista as consequências negativas que as concepções favoráveis à terapias ou tratamentos relativos à cura da homessexualidade têm na vida das pessoas LGBT, procurou-se identificar se haviam medidas prévias deste construto no contexto internacional e nacional, realizando-se buscas no dia 27 maio de 2019 nas bases Index Psi, PubMed, Scielo, LILACS e Google Acadêmico, utilizando diferentes descritores: "beliefs about curing homosexuality" e "scale" e "crenças sobre a cura da homossexualidade" e "escala". As buscas no contexto internacional permitiram identificar unicamente o estudo desenvolvido por Pereira et al. (2009), que adaptaram escala de crenças sobre a natureza da homossexualidade formada por 15 itens (e.g., as causas da homossexualidade estão relacionadas com disfunções hormonais; as causas da homossexualidade estão relacionadas com a falta de carácter). Os autores aplicaram a escala em uma amostra de 482 estudantes universitários portugueses e encontraram uma estrutura fatorial formada por cinco componentes (crenças religiosas; crenças ético-morais; crenças psicológicas; crenças biológicas; crenças psicossociais).

No âmbito nacional foi possível identificar os estudos de Lacerda et al. (2002) e Cerqueira-Santos et al. (2007). Nessa direção, Lacerda et al. (2002) construíram a escala de explicações sobre a homossexualidade composta por 15 itens (e.g., as causas da homossexualidade estão relacionadas ao descumprimento da palavra de Deus; as causas da homossexualidade estão relacionadas a abusos sexuais sofridos na primeira infância). Os autores aplicaram a escala em uma amostra de 220 estudantes universitários da cidade de João Pessoa e encontraram uma estrutura fatorial composta por cinco explicações sobre a homossexualidade (explicações biológicas, ético-morais, religiosas, psicológicas e psicossociais). Cerqueira-Santos et al. (2007), por sua vez, construíram a escala de crenças sobre homossexualidade composta por 29 itens (e.g., gays, em geral, são mais promíscuos do que homens heterossexuais; lésbicas afastam-se de preceitos religiosos). A escala foi aplicada em uma amostra de 442 estudantes universitários e por meio da análise fatorial os autores identificaram uma estrutura formada por três componentes (representação negativa de gays e lésbicas, representação positiva e diferenciação intergrupal entre gays e lésbicas).

Em resumo, diante dos achados das buscas realizadas, parece evidente o interesse da comunidade científica acerca das crenças sobre a natureza da homossexualidade. Não obstante, não existem medidas psicométricas adequadas para dimensionar as crenças em torno da cura da homossexualidade. Dessa forma, o presente estudo procura oferecer uma contribuição a temática, descrevendo o processo de elaboração de um instrumento voltado para mensuração de tais crenças, checando evidências psicométricas preliminares (validade fatorial, discriminante e convergente) e consistência interna.

\section{Método}

\section{Participantes}

Participaram da pesquisa 225 estudantes de uma instituição pública de ensino superior de João Pessoa (PB), tendo uma média de idade de 21.3 anos 
$(D P=5.78$; variando de 18 a 59 anos $)$. A maioria indicou ser do sexo feminino (68.5\%), medianamente religiosa (42.7\%), heterossexual (78.6\%) e de classe econômica média (46.4\%). Estes foram selecionados por técnicas de amostragem não probabilística, segundo conveniência do pesquisador, considerando como critérios de inclusão ter idade igual ou superior a 18 anos de idade e concordar em participar voluntariamente do estudo.

\section{Elaboração da Escala de Crenças sobre a Cura da Homossexualidade}

Pasquali(2010a) entende que entre os problemas associados às medidas psicológicas, um ponto frágil se refere à sistematização do fenômeno, sugerindo que com uma fundamentação teórica coesa, torna-se possível definir operacionalmente o construto. Portanto, partindo de uma revisão da literatura (CerqueiraSantos et al., 2007; Lacerda et al., 2002; Pereira et al., 2009; Pereira et al., 2017) os itens da ECCH foram organizados em cinco dimensões hipotéticas, sendo as mesmas denominadas de crenças religiosas (baseadas na ideia de que a homossexualidade requer cura, pois é tida como uma predisposição para o pecado e desobediência ao que se julga serem as leis de Deus), crenças morais (ancoradas na ideia de que a homossexualidade precisa ser curada, pois é caracterizada por uma tendência de transgredir os valores morais, incluindo o que se acredita ser o valor da moralidade e das boas maneiras); crenças psicológicas (noção de que a homossexualidade necessita de tratamento ou cura, já que a mesma é consequência de situações traumáticas vivenciadas na infância, tais como abuso sexual ou má relação com as figuras parentais); crenças biológicas (fundamentadas na noção de que a homossexualidade precisa ser curada, pois a mesma têm uma essência de natureza genética, que é transmitida hereditariamente e que se manifesta a partir de disfunções hormonais); e por fim, as crenças desfavoráveis à reversão sexual (representa uma noção de que a homossexualidade não necessita de tratamento ou cura, uma vez que a mesma diz respeito apenas a uma expressão de sexualidade humana).

A definição constitutiva supracitada norteou a operacionalização do construto, guiando a escolha e/ou redação dos itens. A partir disso, tomando em conta os critérios de adequação, relevância e clareza (Pacico, 2015), elaboraram-se 36 itens, os quais foram submetidos à análise teórica, checando evidências de sua validade baseada em conteúdo.

\section{Validade Baseada em Conteúdo da Medida de Crenças sobre a Cura da Homossexualidade}

Inicialmente, os 36 itens foram submetidos à apreciação de seis juízes, peritos da área da Psicologia Social e Psicometria, sendo todas do sexo feminino, tendo média de idade de 29 anos ( $\mathrm{DP}=2,06)$. Todos os juízes apresentaram a titulação de Doutor, vinculados a instituções de Ensino Superior: Universidade Federal da Paraíba (20\%), Faculdade de Ciências Médicas (10\%), Universidade Federal do Mato Grosso do Sul (10\%), Universidade Cruzeiro do Sul São Paulo (10\%), e Massey University (10\%). Utilizando os critérios de adequação do item ao construto, relevância do item ao construto e clareza na redação do item, os juízes analisaram os itens a partir da definição constitutiva anteriormente apresentada.

Destaca-se que o critério de adequação verifica se o item elaborado avalia o construto de interesse em determinada população, devendo os juízes avaliarem quão bem o item representava o construto. O critério da relevância, por sua vez, analisa a importância do item para a descrição do construto. Por fim, o critério de clareza verifica se a linguagem ou a redação de cada item está de acordo com as características da população-alvo, isto é, se a redação de cada item é clara, adequada e compreensível para as pessoas que potencialmente responderão o instrumento. Os critérios foram avaliados em uma escala variando de 0 (nada) a 10 (totalmente); o cálculo do coeficiente de validade de conteúdo considera o número de juízes e sua média de respostas, 
Tabela 1.

Índices de CVC na Análise dos Juízes

\begin{tabular}{|c|c|c|c|}
\hline \multirow{2}{*}{ Itens } & \multicolumn{3}{|c|}{ Coeficiente de Validade de Conteúdo (CVC) } \\
\hline & Adequação & Relevância & Clareza \\
\hline 01 & 0.98 & 0.92 & 0.98 \\
\hline 02 & 0.98 & 0.97 & 0.98 \\
\hline 03 & 0.95 & 0.92 & 1.00 \\
\hline 04 & 0.95 & 0.92 & 0.85 \\
\hline 05 & 0.98 & 0.95 & 0.90 \\
\hline 06 & 0.93 & 0.97 & 0.93 \\
\hline 07 & 0.85 & 0.92 & 0.80 \\
\hline 08 & 1.00 & 1.00 & 0.90 \\
\hline 09 & 0.95 & 0.95 & 0.95 \\
\hline 10 & 0.95 & 0.95 & 0.95 \\
\hline 11 & 0.97 & 0.96 & 1.00 \\
\hline 12 & 0.95 & 1.00 & 0.95 \\
\hline 13 & 0.93 & 0.97 & 0.90 \\
\hline 14 & 0.95 & 0.92 & 0.93 \\
\hline 15 & 0.95 & 0.95 & 0.98 \\
\hline 16 & 0.95 & 0.95 & 0.98 \\
\hline 17 & 0.90 & 0.90 & 1.00 \\
\hline 18 & 0.95 & 0.90 & 0.98 \\
\hline 19 & 0.93 & 0.90 & 0.98 \\
\hline 20 & 1.00 & 1.00 & 1.00 \\
\hline 21 & 0.98 & 0.97 & 1.00 \\
\hline 22 & 0.98 & 0.97 & 0.98 \\
\hline 23 & 0.80 & 0.80 & 0.75 \\
\hline 24 & 0.85 & 0.85 & 1.00 \\
\hline 25 & 0.98 & 0.97 & 0.95 \\
\hline 26 & 0.93 & 0.92 & 1.00 \\
\hline 27 & 0.93 & 0.92 & 1.00 \\
\hline 28 & 0.93 & 0.92 & 0.92 \\
\hline 29 & 0.95 & 0.95 & 1.00 \\
\hline 30 & 0.98 & 0.97 & 0.98 \\
\hline 31 & 0.98 & 0.97 & 1.00 \\
\hline 32 & 0.85 & 0.97 & 0.85 \\
\hline 33 & 0.95 & 0.95 & 0.98 \\
\hline 34 & 0.98 & 0.97 & 1.00 \\
\hline 35 & 0.95 & 0.97 & 0.93 \\
\hline 36 & 1.00 & 1.00 & 0.98 \\
\hline
\end{tabular}


podendo este coeficiente se referir a cada item ou ao conjunto de itens. Adotou-se como ponto de corte o valor de 0.70 como indicativo de adequação do item (Cassepp-Borges et al., 2010). Os resultados do CVC podem ser observados na tabela 1 .

De acordo com a tabela 1, todos os 36 itens apresentaram evidências de validade baseadas em conteúdo, obtendo $C V C$ acima de 0.70 . Portanto, atenderam aos critérios estabelecidos, isto é, clareza, relevância e pertinência. Desse modo, esta versão experimental da ECCH foi considerada para conhecer evidências de sua validade fatorial, convergente e discriminante, bem como a consistência interna, sendo objeto principal da pesquisa ora descrita.

\section{Instrumentos}

Os participantes responderam um questionário com perguntas demográficas (idade, classe social, orientação sexual, religiosidade e sexo) e as três seguintes medidas:

Escala de Crenças sobre a Cura da Homossexualidade (ECCH): conforme descrita previamente, esta medida é formada por 36 itens (e.g., "devem-se incentivar mais campanhas mostrando que a homossexualidade é uma patologia, e que, portanto, pode ser curada"; "a homossexualidade diz respeito a uma alteração fisiológica, sendo possíveis tratamentos que promovam sua cura"). Estes são respondidos em uma escala de cinco pontos do tipo Likert, variando de 1 (discordo totalmente) a 5 (concordo totalmente).

Escala de Crenças sobre Homossexualidade $(E C H)$ : originalmente proposta por Cerqueira-Santos et al. (2007), a escala é composta de 29 itens, sendo distribuídos em três dimensões: representação negativa de gays e lésbicas (e.g., "gays usam mais drogas do que homens heterossexuais"; $\alpha=0.89$ ), representação positiva (e.g., "lésbicas são pessoas criativas e divertidas"; $\alpha=0.69)$ e $d i$ ferença intergrupal de gays e lésbicas (e.g., "gays afeminados são, em geral, mais discriminados do que gays masculinizados"; $\alpha=0.69$ ). Os itens são respondidos em uma escala do tipo Likert, variando de 1 (concordo inteiramente) a 5 (discordo inteiramente). No presente estudo a consistência interna (alfa de cronbach) da medida foi de 0.89 .

Escala de Desejabilidade Social de Marlowe-Crowne (EDSMC): originalmente desenvolvida por Crowne e Marlowe (1960) e adaptada para o contexto brasileiro por Gouveia et al. (2009). A presente medida contém 20 itens (e.g., "se pudesse entrar em um cinema sem pagar e ter certeza que não seria visto(a), provavelmente eu o faria"; "sou sempre cuidadoso(a) com meu jeito de vestir") distribuídos em uma estrutura unifatorial, que expressam condutas que podem indicar uma necessidade de aprovação por parte dos outros. Para respondê-los, o participante deve assinalar verdadeiro (1) ou falso (0), tomando como base seu comportamento. A consistência interna da escala no presente estudo foi de 0.79 .

\section{Procedimento}

A coleta de dados teve lugar em uma universidade pública, de acordo com as seguintes etapas: (a) levantamento de e-mails de docentes responsáveis pelas disciplinas; (b) envio de mensagem solicitando a disponibilização de turmas para a coleta de dados e definição de horário de conveniência; e (c) coleta de dados propriamente marcada. Neste caso, os aplicadores se apresentavam aos participantes e explicitavam os objetivos da pesquisa, reiterando a confidencialidade de suas respostas, informando-lhes sobre a possibilidade de desistir da participação sem qualquer ônus. A coleta foi realizada em contexto coletivo de sala de aula, porém as respostas foram dadas individualmente. Seguiram-se procedimentos éticos consoantes com a Resolução 510/16, obtendo-se aprovação do Comitê de Ética correspondente (CAAE: 8892719.6.0000.5188). Em média, 15 minutos foram suficientes para concluir a participação no estudo. 


\section{Análise de Dados}

A análise dos dados foi realizada com o software SPSS (Versão 23). Calcularam-se estatísticas descritivas para caracterizar os participantes do estudo, Teste $t$ para medidas independentes para checar o poder discriminativo dos itens e análise de componentes principais (ACP) para identificar a estrutura fatorial da medida. No caso, avaliou-se a adequação desta análise por meio do KMO e Teste de Esfericidade de Bartlett. Ademais, realizou-se análises de correlação $r$ de Pearson para averiguar evidências de validade convergente e discriminante. Por fim, calculou-se o alfa de Cronbach. Ressalta-se que a escolha pela análise de componentes principais baseou-se na facilidade de interpretação da estrutura e a possibilidade de considerar independentemente os cinco componentes (para uma maior discussão ver Damásio, 2012).

\section{Resultados}

Inicialmente, verificou-se a qualidade métrica dos itens, isto é, se estes conseguiam discriminar participantes com magnitudes próximas no traço latente. Neste sentido, realizou-se o somatório dos 36 itens da $E C C H$, estabelecendo grupos inferior e superior, com base na mediana empírica $(M d=1.11)$. Posteriormente, por meio de um Teste $t$ para medidas independentes, as médias de cada item foram comparadas entre os grupos-critério. Todos os itens apresentaram um poder discriminativo significativo $(p<0.05)$, sendo incluídos na análise posterior.

Previamente aos procedimentos exploratórios para conhecer a estrutura interna da $\mathrm{ECCH}$, avaliou-se a fatorabilidade dos dados por meio dos critérios de Kaiser-Meyer-Olkin (KMO) e Teste de Esfericidade de Bartlett. Os achados apoiaram a realização da $\mathrm{ACP}$, evidenciando a possibilidade de extrair ao menos uma dimensão subjacente aos itens $\left[K M O=0.94\right.$ e $\chi^{2}(630)=10128,424$, $p<0.001]$. Desse modo, procedeu-se a este tipo de análise. No caso, visando identificar o número de fatores (componentes) a extrair, consideraram-se diferentes critérios: o Kaiser (valor próprio igual ou superior a 1) indicou uma estrutura com cinco componentes, cujos valores próprios variaram entre 21.7 a 1.01 , explicando conjuntamente $81.76 \%$ da variância total; e o Cattell (distribuição gráfica dos valores próprios) sugeriu uma estrutura de cinco componentes. Visando corroborar os critérios anteriores, utilizou-se um terceiro critério: a análise paralela (critério de Horn), que é mais robusto (Doriban \& Owen, 2019). Neste caso, adotaram-se os parâmetros do banco de dados (225 participantes e 36 variáveis), realizando 1.000 simulações, atestando a adequação de reter cinco componentes.

Portanto, realizou-se uma nova $A C P$ [KMO = 0,94 e Teste de Esfericidade de Bartlet, $\chi^{2}$ (630) $=10128,424, p<0.001]$, fixando a extração de cinco componentes e adotando rotação varimax. Os critérios para a retenção dos fatores corroboraram a estrutura pentafatorial: apenas cinco valores próprios superiores a 1 (Kaiser) e o sexto valor simulado foi superior ao observado (Horn). Partindo do princípio da parcimônia, útil sobretudo quando se considera o contexto de pesquisa com múltiplas medidas e em contextos transculturais (Borsa et al., 2012), decidiu-se reduzir o conjunto de itens desta medida, tornando-a mais fácil e cômoda de ser aplicada. Primou-se por obter um número idêntico de itens por dimensão, considerando o mínimo viável para representar um construto latente.

Diante disso, optou-se reter quatro itens com as maiores cargas fatoriais por componente, resultando em uma medida com 20 itens, os quais foram submetidos à nova $A C P[K M O=0.93$ e Teste de Esfericidade de Bartlet, $\chi^{2}(190)=5117,155 p$ $<0.001]$. Os critérios para a retenção dos fatores indicaram uma estrutura pentafatorial, com cinco valores próprios superiores a 1 (Kaiser) e o sexto valor simulado foi superior ao observado (Horn). Os resultados desta análise são mostrados na tabela 2 a seguir. 
Tabela 2.

Estrutura fatorial da Escala de Crenças sobre a Cura da Homossexualidade

\begin{tabular}{|c|c|c|c|c|c|}
\hline Itens & I & II & III & IV & $\mathbf{V}$ \\
\hline $\begin{array}{l}\text { 09. É possível que uma pessoa homossexual mude sua } \\
\text { orientação sexual por meio de sua fé em Deus. }\end{array}$ & 0.87 & 0.14 & 0.24 & 0.14 & 0.21 \\
\hline $\begin{array}{l}\text { 10. Por meio da obediência à palavra de Deus, é possível } \\
\text { alcançar a "cura gay" }\end{array}$ & 0.84 & 0.22 & 0.15 & 0.24 & 0.15 \\
\hline $\begin{array}{l}\text { 12. É possível mudar a orientação homossexual para } \\
\text { heterossexual por meio da fé religiosa. }\end{array}$ & 0.83 & 0.20 & 0.23 & 0.22 & 0.23 \\
\hline $\begin{array}{l}\text { 15. Aceitando a palavra de Deus, os homossexuais } \\
\text { conseguiriam mudar de orientação sexual. }\end{array}$ & 0.83 & 0.19 & 0.27 & 0.13 & 0.26 \\
\hline $\begin{array}{l}\text { 31. O comportamento homossexual deve ser submetido a } \\
\text { tratamento, pois está relacionado com falta de caráter. }\end{array}$ & 0.10 & 0.86 & 0.17 & 0.24 & 0.14 \\
\hline 32. Os homossexuais são pessoas imorais que devem se tratar. & 0.16 & 0.88 & 0.20 & 0.27 & 0.16 \\
\hline $\begin{array}{l}\text { 33. É importante o estabelecimento de tratamentos para } \\
\text { a "cura gay", pois os homossexuais são responsáveis por } \\
\text { deteriorar os valores morais da sociedade. }\end{array}$ & 0.30 & 0.81 & 0.21 & 0.29 & 0.22 \\
\hline $\begin{array}{l}\text { 34. É necessário tratamento para curar o comportamento } \\
\text { imoral dos homossexuais. }\end{array}$ & 0.28 & 0.82 & 0.28 & 0.22 & 0.19 \\
\hline $\begin{array}{l}\text { 03. É recomendável que se promovam políticas de mudança } \\
\text { de orientação sexual, uma vez que a homossexualidade é uma } \\
\text { má formação genética durante a gestação }\end{array}$ & 0.15 & 0.28 & 0.79 & 0.23 & 0.23 \\
\hline $\begin{array}{l}\text { 05. Devem-se incentivar mais campanhas mostrando que a } \\
\text { homossexualidade é uma patologia, e que, portanto, pode ser } \\
\text { curada. }\end{array}$ & 0.16 & 0.27 & 0.82 & 0.23 & 0.21 \\
\hline $\begin{array}{l}\text { 06. A "cura gay" deve ser incentivada pelos profissionais, uma } \\
\text { vez que os homossexuais apresentam uma anomalia hormonal. }\end{array}$ & 0.24 & 0.28 & 0.77 & 0.28 & 0.22 \\
\hline $\begin{array}{l}\text { 07. A homossexualidade diz respeito a uma alteração fisiológica, } \\
\text { sendo possíveis tratamentos que promovam sua cura. }\end{array}$ & 0.27 & 0.27 & 0.73 & 0.32 & 0.14 \\
\hline $\begin{array}{l}\text { 23. A homossexualidade diz respeito à expressão de identidade } \\
\text { do indivíduo, não requerendo qualquer tratamento. }\end{array}$ & -0.27 & -0.19 & -0.15 & -0.79 & -0.16 \\
\hline $\begin{array}{l}\text { 24. A homossexualidade é apenas uma forma de orientação sexual } \\
\text { possível, dispensando qualquer tratamento ou ideia de cura. }\end{array}$ & -0.30 & 0.26 & -0.31 & -0.82 & -0.21 \\
\hline $\begin{array}{l}\text { 25. A homossexualidade não é uma doença e, portanto, não } \\
\text { precisa ser curada. }\end{array}$ & -0.20 & -0.27 & -0.36 & -0.73 & -0.31 \\
\hline $\begin{array}{l}\text { 26. O comportamento homossexual não está ligado a qualquer } \\
\text { transtorno psicológico. }\end{array}$ & -0.25 & -0.52 & -0.51 & -0.54 & -0.29 \\
\hline $\begin{array}{l}\text { 19. A homossexualidade é uma perversão sexual, requerendo } \\
\text { tratamento psicológico. }\end{array}$ & 0.30 & 0.29 & 0.34 & 0.23 & 0.71 \\
\hline $\begin{array}{l}\text { 20. A homossexualidade é uma perturbação psicológica que } \\
\text { necessita de acompanhamento psicológico para indivíduos que } \\
\text { queiram se curar. }\end{array}$ & 0.24 & 0.23 & 0.26 & 0.25 & 0.82 \\
\hline
\end{tabular}




\begin{tabular}{|c|c|c|c|c|c|}
\hline Itens & $\mathbf{I}$ & II & III & IV & $\mathbf{V}$ \\
\hline $\begin{array}{l}\text { 21. A homossexualidade é um desvio de gênero, podendo ser } \\
\text { tratado com ajuda de psicólogo. }\end{array}$ & 0.24 & 0.35 & 0.38 & 0.32 & 0.77 \\
\hline $\begin{array}{l}\text { 22. Os homossexuais são portadores de um transtorno } \\
\text { psicológico, requerendo tratamento para a sua cura. }\end{array}$ & 0.22 & 0.29 & 0.31 & 0.27 & 0.74 \\
\hline Número de itens & 4 & 4 & 4 & 4 & 4 \\
\hline Valor Próprio & 12.3 & 1.84 & 1.42 & 1.04 & 1.04 \\
\hline \% de variância & 61.5 & 9.23 & 7.10 & 5.23 & 4.26 \\
\hline Alfa de Cronbach & 0.95 & 0.95 & 0.96 & 0.93 & 0.92 \\
\hline
\end{tabular}

Nota: I (Crenças religiosas); II (Crenças morais); III (Crenças biológicas); IV (Crenças desfavoráveis à reversão sexual); V (Crenças psicológicas).

Verificou-se que estes componentes explicaram, conjuntamente, $87.35 \%$ da variância total. Descreve-se a seguir cada um dos componentes:

Componente I. Este componente apresentou valor próprio de 12.3 correspondendo à explicação de $61.5 \%$ da variância total. Os quatro itens apresentaram cargas fatoriais variando de 0.83 (Item 15 . "Aceitando a palavra de Deus, os homossexuais conseguiriam mudar de orientação sexual") a 0.87 (Item 09. É possivel que uma pessoa homossexual mude sua orientação sexual por meio de sua fé em Deus). Neste sentido, pareceu adequado defini-lo como crenças religiosas, referindo-se a ideia de que a homossexualidade é um pecado e que precisa ser curada/tratada por meio da fé ou da palavra de Deus. Sua consistência interna (alfa de Cronbach) foi de 0.95 .

Componente II. Seu valor próprio foi de 1.84 (9.23 \% da variância total). Os quatro itens que o compõe apresentaram cargas fatoriais entre 0.82 (Item 34. É necessário tratamento para curaro comportamento imoral dos homossexuais) a 0.86 (Item 31. O comportamento homossexual deve ser submetido a tratamento, pois está relacionado com falta de caráter). Seu conteúdo pareceu claro, recebendo o nome de crenças morais, reunindo itens que expressam a concepção de que a homossexualidade é considerada uma transgressão aos valores morais da família, devendo assim ser curada. Ele apresentou consistência interna adequada $(\alpha=0.95)$.

Componente III. Este apresentou valor próprio de 1.42 (7.10 \% da variância total), reunindo quatro itens com cargas fatoriais entre 0.73 (Item 07. A homossexualidade diz respeito a uma alteração fisiológica, sendo possíveis tratamentos que promovam sua cura) a 0.82 (Item 05. Devem-se incentivar mais campanhas mostrando que a homossexualidade é uma patologia, e que, portanto, pode ser curada), sendo nomeado como crenças biológicas. Este componente concebe a ideia de que a homossexualidade diz respeito a uma má formação genética durante a gestação, necessitando assim de tratamento para ser curada. Seu alfa de Cronbach $(\alpha)$ foi de 0.96 .

Componente $I V$. Seu valor próprio foi de 1.04 (5.23\% da variância total), sendo composto por quatro itens com saturações entre -0.54 (Item 26. O comportamento homossexual não está ligado a qualquer transtorno psicológico) a -0.82 (Item 24. A homossexualidade é apenas uma forma de orientação sexual possível, dispensando qualquer tratamento ou ideia de cura). De acordo com seu conteúdo, decidiu-se nomeá-lo como crenças desfavoráveis à reversão sexual, uma vez que os itens descrevem a percepção de que a homossexualidade diz respeito unicamente a uma expressão de identidade sexual, não requerendo assim nenhuma 
forma de cura. Este componente teve índice de consistência interna (alfa de Cronbach) de 0.93.

Componente V. Este último componente teve valor próprio de 1.04 , explicando $4.26 \%$ da variância total; seus quatro itens apresentaram cargas fatoriais variando de 0.71 (Item 19. A homossexualidade é uma perversão sexual, requerendo tratamento psicológico) a 0.82 (Item 20. A homossexualidade é uma perturbação psicológica que necessita de acompanhamento psicológico para indivíduos que queiram se curar). Reuniu itens que sugerem a crença de que a homossexualidade é resultado de traumas psicológicos sofridos na infância, precisando assim ser curada. A partir disso, decidiu-se nomear este componente de crenças psicológicas, indicando uma precisão adequada $(\alpha=0.92)$.

Posteriormente a definição da estrutura fatorial, optou-se por verificar evidências de validade convergente e discriminante da $E C C H$. Para tal, os escores das dimensões foram computados a partir da soma dos itens que os compõem, e correlacionados com aqueles da Escala de Crenças sobre a Homossexualidade e Desejabilidade Social. Os coeficientes de correlação estão descritos na tabela 3 .

Os resultados encontrados apontaram, principalmente, para correlações positivas entre representação negativa de gays e lésbicas e as crenças biológicas $(r=0.39 ; p<0.001)$, religiosas $(r=$ $0.50 ; p<0.001)$, psicológicas $(r=0.44 ; p<0.001)$ e morais $(r=0.39 ; p<0.001)$, bem como uma relação negativa com a crença psicossocial $(r=-0.45$; $p<0.001)$. Em relação às dimensões representação positiva, diferença intergrupal e desejabilidade social, não foi possível observar nenhuma relação significativa com o conjunto de crenças.

\section{Discussão}

O objetivo desse estudo foi desenvolver um instrumento para avaliar crenças sobre cura da homossexualidade, verificando suas evidências de sua validade fatorial e consistência interna. Inicialmente, discute-se o processo de elaboração desse instrumento, denominado como Escala de Crenças sobre a Cura da Homossexualidade (ECCH), e, posteriormente, suas evidências psicométricas; no final são tratadas algumas limitações potenciais do estudo e recomendações sobre pesquisas futuras.

\section{Processo de construção da ECCH}

No que concerne ao processo de elaboração dos itens, consideraram-se procedimentos teóricos, empíricos e analíticos, na linha da recomendação de Pasquali (2010b). Desta forma, parece evidente o cuidado para a construção da $E C C H$, conforme previamente descrito. Concretamente, consultou-se a literatura sobre o construto crenças sobre a cura da homossexualidade, procurando sistematizar o marco teórico que embasou o instrumento (Cerqueira-Santos et al., 2007; Lacerda et al., 2002). Nesta direção, definiu-se constitutivamente o construto em consonância com a

Tabela 3.

Evidências de validade convergente e discriminante da ECCH

\begin{tabular}{|c|c|c|c|c|c|}
\hline Dimensões & $C B$ & $C R$ & $\boldsymbol{C P}$ & CDRS & $C M$ \\
\hline Representação negativa de gays e lésbicas & $0.39 * *$ & $0.50 * *$ & $0.44 * *$ & $-0.45 * *$ & $0.39 * *$ \\
\hline Representação positiva & -0.06 & -0.09 & -0.02 & -0.05 & -0.05 \\
\hline Diferença intergrupal de gays e lésbicas & -0.05 & -0.03 & $-0.06-$ & -0.10 & -0.03 \\
\hline Desejabilidade Social & 0.08 & 0.12 & 0.10 & 0.10 & 0.12 \\
\hline
\end{tabular}

Nota: *correlações estatisticamente significativas ao nível de 0,05 ; **orrelações estatisticamente significativas ao nível de 0,$01 ;$ СB (crenças biológicas); $\mathrm{CR}$ (crenças religiosas); $\mathrm{CP}$ (crenças psicológicas); CDRS (crenças desfavoráveis à reversão sexual); $\mathrm{CM}$ (crenças morais). 
literatura (Pereira et al., 2009; Pereira et al., 2017; Pereira et al., 2014).

O passo seguinte foi operacionalizar o construto, criando novos itens, tentando representar toda sua extensão, além de seguir os critérios sugeridos por Pasquali (2010a) para redação/escolha dos itens: clareza (o item deve ser inteligível até para o estrato mais baixo da população-meta, utilizando frases curtas e expressões simples), simplicidade (um item deve expressar uma única ideia), comportamental (o item deve expressar um comportamento, não uma abstração) e credibilidade (a formulação do item de modo que não pareça "infantil”"). Após reunir o conjunto de itens, procurou-se analisar sua adequação, considerando especialistas na área de interesse (Pasquali, 2010b). Desta forma, os itens foram submetidos à análise de seis juízes que têm atuado em Psicometria e Psicologia Social, os quais avaliaram cada item em termos dos critérios de pertinência, adequação (semântica e teórica) e clareza.

Por fim, realizaram-se os procedimentos empíricos e analíticos, compreendendo tratamento estatístico e análise dos itens (Pasquali, 2012). Nesta conjuntura, órgãos da American Educational Research Association, American Psychological Association e National Council on Measurement in Education (AERA et al., 1999) preconizam que a verificação da validade compreende uma das condições mais fundamentais quando se trata da construção e análise de instrumentos, pois revela as suas qualidades psicométricas (Reppold et al., 2014). Neste sentido, realizaram-se análise de poder discriminativo dos itens, além de verificação de evidências de validade fatorial, convergente e discriminante, bem como a consistência interna.

\section{Evidências psicométricas da ECGC}

A $E C C H$, no conjunto, parece uma medida psicometricamente adequada. Seus itens mostraram poder discriminativo satisfatórios, permitindo diferenciar respondentes com pontuações próximas no construto avaliado (Pasquali, 2012). Sua estrutura pentafatorial emergiu sem fixar o número de componentes, revelando-se adequada inclusive quando se empregou critério mais robusto, como a análise paralela (Doriban \& Owen, 2019). Os indicadores de consistência interna desta medida foram adequados para fins de pesquisa, tendo alfa de Cronbach superiores a 0.70 (Viladrich et al., 2017).

Adicionalmente a verificação da validade fatorial da $E C C H$, buscou-se reunir mais evidências acerca da validade do instrumento, testando as validades convergente e discriminante. De acordo com Pasquali (2003) um instrumento possui validade de convergente quando os escores do instrumento analisado apresentam relações em direção e magnitudes esperadas (Valentini \& Damásio, 2016). Especificamente no contexto da presente pesquisa, a relação positiva entre representação negativa de gays e lésbicas e as crenças (religiosas, biológicas, morais e psicológicas) era esperada. Em termos teóricos, o endosso a crença de que os homossexuais são mais promíscuos, que apresentam tendência a contaminação de infecções sexualmente transmissíveis (IST's) e afastamento a preceitos religiosos, faz com que com a homossexualidade seja vista como uma forma de transgressão aos valores morais, sendo necessário um "ajustamento" dos indivíduos que compõe a comunidade LGBT (Cerqueira-Santos et al., 2007). Em contrapartida, foi possível observar uma relação inversa entre representação negativa de gays e lésbicas e as crenças desfavoráveis, tendo em vista que indivíduos que compreendem a homossexualidade apenas como uma expressão de identidade e orientação sexual, tendem a ver os homossexuais como pessoas normais e socialmente ajustadas (Mesquita, 2018).

Já a validade discriminante se refere a capacidade de a medida proposta não ser modificada ou relacionada a processos teoricamente não relacionados (Henseler et al., 2015), isto é, quando a medida possui correlação nula ou não significativa com um instrumento que difere teoricamente da mesma, ela possui validade discriminante. Dentro do escopo da 
pesquisa, observou-se uma relação não significativa entre o conjunto de crenças e a desejabilidade social. Tal resultado era esperado, uma vez que a desejabilidade social caracteriza uma tendência que as pessoas têm de se mostrarem mais positivas aos olhos dos demais, mascarando assim seus reais valores, atitudes e crenças. Nesse sentido, os indivíduos tendem a não expressar explicitamente atitudes preconceituosas frente a minorais sociais (e.g., homossexuais, negros) devido a existência de normas legais que proíbem tal comportamento (Soares et al., 2016). Em resumo, todas as dimensões da ECCH apresentaram validade convergente e discriminante.

A dimensão crenças religiosas agrupou itens que representam a ideia de que a homossexualidade diz respeito a uma predisposição para o pecado e para desobediência ao que se julga serem as leis de Deus, sendo necessário que seja curada. Dentro dessa conjuntura é possível citar a criação em 2013 da Frente Parlamentar Evangélica do Congresso Nacional (FPE), que tem como objetivo defender os interesses da comunidade evangélica e atuam como oposição a aprovação de projetos que ferem preceitos bíblicos, tais como a oficialização de direitos legais para os homossexuais (e.g., casamento civil, adoção). Nessa direção a crença religiosa de que a homossexualidade requer cura estaria atrelada a reações que desqualificam a diversidade sexual, havendo a tendência de perceber a expansão e aceitação dos direitos LGBT's como uma ameaça a ordem social (Quintão, 2017).

A dimensão crenças morais foi formada por itens que constituem a ideia de que a homossexualidade precisa ser erradicada/curada tendo em vista que esse tipo de orientação sexual é caracterizada pela tendência das pessoas a violarem os valores morais, incluindo o que se acredita ser o valor de decência e boas maneiras. Atrelada a essa ideia, a literatura indica que os discursos voltados para a favorabilidade da chamada "cura gay" estão relacionadas a ideia de que a comunidade LGBT representa um perigo aos valores e normas que são considerados ideais para uma sociedade, a exemplo dos valores de família e de tradição (Albuquerque, 2016).

A dimensão crenças biológicas reuniu itens que partem da premissa que a homossexualidade deve ser curada, uma vez que sua essência é de natureza genética, sendo transmitida hereditariamente e que se manifesta mediante disfunções hormonais. De acordo com Sousa (2017), o pensamento de que a homossexualidade é uma anomalia genética remota da obra de Richard Von Krafft-Ebing denominada Psychopatia Sexualis (Psicopatia do Sexo), que enquadrava a homossexualidade como uma forma de anormalidade denominada de $p a$ raestesia (desejo sexual sobre um objeto inadequado ou errôneo). Historicamente, a publicação do autor em questão serviu de base para legitimar uma visão estigmatizada de que a homossexualidade era uma forma de "anomalia genética". Análoga a essa discussão, Campos e Guerra (2016) elencam que a homossexualidade inserida nesse processo de patologizacão e diferente do padrão heteronormativo, favoreceu a construção da crença de que homossexuais são pessoas desviantes à regra, ou seja, anormais. As autoras ainda ressaltam que tal processo age como base para a expressão do preconceito e da discriminação.

Quanto à dimensão crenças desfavoráveis à reversão sexual, esta foi formada por itens que expressam a ideia de que a homossexualidade não necessita de tratamento ou cura, tendo em vista que a mesma não se configura como um desvio, mas sim como uma forma normal de orientação sexual. Nesta linha, órgãos vinculados a saúde (e.g., Conselho Federal de Medicina e de Psicologia) retiraram a homossexualidade como uma doença, modificando o termo sufixo "ismo" por "dade". Desse modo, os homossexuais passaram de "doentes" para seres normais, sendo a atração pelo mesmo sexo não mais uma enfermidade, mas sim, o modo que estes indivíduos escolhem para expressar sua identidade sexual (Costa \& Nardi, 2015). 
Por fim, a dimensão crenças psicológicas foi constituída por itens que abordam a necessidade da cura da homossexualidade, por esta ser resultado de traumas psicológicos sofridos na infância (e.g., abuso sexual, má relação com a figura parental). Em outras palavras, inerente a este componente está a ideia de que a homossexualidade é uma perturbação psicológica que encontra sua origem em traumas ocorridos durante o período da infância. A esse respeito, é possível mencionar que durante décadas profissionais das áreas de Medicina, Psiquiatria e Psicologia buscaram formas de tratamento para curar pacientes que se autodeclaravam homossexuais, sendo esses indivíduos enquadrados na categoria de perturbações psicossociais (Mesquita, 2018).

Para além dos resultados psicométricos encontrados no presente estudo, nosso argumento é que ter uma escala que mensure as crenças sobre a cura da homossexualidade é de suma importância, uma vez que tais crenças vão além da discriminação contra as minorias sexuais, porque é um tipo de crença que, quando levada ao extremo, visa proibir a homossexualidade da sociedade. Em outras palavras, é muito provável que aqueles que apoiam mais fortemente o estabelecimento de tratamentos para a "cura gay" sejam motivados pelo desejo de acabar com qualquer tipo de prática homoafetiva (e.g., casamento, adoção), sendo essa uma forma velada de extermínio de um grupo socialmente estigmatizado. Assim, pessoas mais normativas que apoiam a manutenção do comportamento heterossexual não apenas querem se distanciar dos homossexuais, mas também apoiam e justificam a eliminação dessa expressão de sexualidade (Aragusuku \& Lara, 2019).

Isso implica pensar no preconceito frente às minorias sexuais como um fenômeno que não se restringe unicamente às disposições individuais (e.g., atitudes, traços de personalidade), mas abarca determinantes históricos, políticos e culturais que são influenciados por dispositivos que normatizam a heterossexualidade como único padrão vigente. A LGBTfobia envolve componentes sociais (culturais e políticos) que estão diretamente relacionados a ideologias que reforçam padrões de opressão institucionalizada contra pessoas não heterossexuais (Anzolin \& Moscheta, 2019; Freires et al., 2019).

Apesar de considerar que os objetivos foram alcançados, algumas limitações são indicadas. Inicialmente, a amostra do estudo, composta por estudantes universitários selecionados por conveniência e com uma quantidade reduzida de participantes; este aspecto limita a generalização dos achados para a população. Como segunda potencial limitação, considera-se unicamente a utilização de análises eminentemente exploratórias. Desse modo, recomendam-se estudos futuros que testem a adequação da $E C C H$ em grupos mais representativos da população brasileira, e se replique estes achados em amostras independentes, visando confirmar a estrutura encontrada por meio da modelagem de equações estruturais.

Por fim, faz-se necessário ampliar o escopo de entendimento das crenças acerca da cura da homossexualidade buscando conhecer a relação das dimensões da $E C C H$ com outros construtos que podem potencialmente se associar, como por exemplo os valores humanos (Gusmão et al., 2016), orientação à dominância social (Giger et al., 2015) e autoritarismo (Cavalcanti, 2016). A esse respeito, estudos na literatura mostram que valores normativos se relacionam positivamente com atitudes mais preconceituosas frente às minorais sexuais (Freires, 2015). Por outro lado, indivíduos que apresentam traços de autoritarismo e orientação à dominância social tendem a estruturar o mundo em hierarquias, atribuindo um maior valor social e político (e.g., acesso a recursos, status social) ao grupo pela qual faz parte, reforçando assim ideologias que envolvem preconceito e apoio a políticas de discriminação frente a grupos minoritários (Etchezahar \& Imhoff, 2017). 


\section{Referências}

Albuquerque, G. A., Parente, J. S., Belém, J. M., \& Garcia, C. D. L. (2016). Violência psicológica em lésbicas, gays, bissexuais, travestis e transexuais no interior do Ceará, Brasil. Saúde em Debate, 40, 100-111. https://doi.org/10.1590/01031104201610908

American Educational Research Association, American Psychological Association \& National Council on Measurement in Education. (1999). Standards for educational and psychological testing. American Educational Research Association.

Anzolin, B., \& Moscheta, M. D. S. (2019). Sentidos sobre Diversidade Sexual e o Trabalho de Psicólogas na Atenção Básica. Psicologia: Ciência e Profissão, 39, 206-221. https://doi. org/10.1590/1982-3703003228644

Aragusuku, H. A., \& Lara, M. F. A. (2019). Uma Análise Histórica da Resolução n ${ }^{\circ}$ 1/1999 do Conselho Federal de Psicologia: 20 Anos de Resistência à Patologização da Homossexualidade. Psicologia: Ciência e Profissão, 39, 6-20. https://doi.org/10.1590/1982-3703003228652

Bartlett,A., Smith, G., \& King, M. (2009). The response of mental health professionals to clients seeking help to change or redirect same-sex sexual orientation. BMC Psychiatry, 9, 2-8. https://doi. org/10.1186/1471-244X-9-11

Borsa, J. C., Damásio, B. F., \& Bandeira, D. R. (2012). Adaptação e validação de instrumentos psicológicos entre culturas: algumas considerações. Paidéia (Ribeirão Preto), 22, 423-432. https://doi.org/10.1590/1982-43272253201314

Campos, L. S., \& Guerra, V. M. (2016). O ajustamento familiar: associações entre o apoio social familiar e o bem-estar de homossexuais. Psicologia Revista, 25, 33-57. https://revistas.pucsp.br/ psicorevista/article/view/29609/20615

Cassal, L. C. B., Bello, H. L., \& Bicalho, P. P. G. D. (2019). Enfrentamento à LGBTIfobia, Afirmação ético-política e regulamentação profissional: 20 anos da Resolução CFP n ${ }^{\circ}$ 01/1999. Psicologia: Ciência e Profissão, 39, 113-128. https://doi. org/10.1590/1982-3703003228516

Cassepp-Borges, V., Balbinotti, M. A. A., \& Teodoro, M. L. M. (2010). Tradução e validação de conteúdo: uma proposta para adaptação de instrumentos. In L. Pasquali (Ed.), Instrumentação psicológica: Fundamentos e práticas (pp. 506-520). Artmed.

Cavalcanti, A. P. R. (2016). Relações entre preconceito religioso, preconceito racial e autoritarismo de direita: uma análise psicossocial (tese de doutorado). Universidade Federal da Paraíba, João Pessoa. https://repositorio.ufpb.br/jspui/ bitstream/tede/9098/2/arquivototal.pdf

Cerqueira-Santos, E., dos Santos Winter, F., Salles, L. A., Longo, J. L., \& Teodoro, M. (2007). Contato interpessoal e crenças sobre homossexualidade: desenvolvimento de uma escala. Interação em Psicologia, 11, 221-229. https://doi.org/10.5380/ psi.v11i2.6639

Conselho Federal de Psicologia. (2017). "Cura gay”. CFP. https://site.cfp.org.br/tag/cura-gay/

Conselho Federal de Psicologia. (2019). STF concede ao CFP liminar mantendo integra e eficaz a resolução 01/99. CFP. https://site.cfp.org.br/stf-concede-ao-cfp-liminar-mantendo-resolucao-01-99

Costa, Â. B., \& Nardi, H. C. (2015). Homofobia e preconceito contra diversidade sexual: debate conceitual. Temas em Psicologia, 23, 715-726. https://doi.org/10.9788/TP2015.3-15

Costa, A. E. O., da Silva, D. M. V., \& Júnior, J. I. L. (2018). Reorientação sexual: compromisso científico ou subterfúgio para cura gay? Gep News, 2, 198-203. http://www.seer.ufal.br/index. php/gepnews/article/view/5272/3702

Crowne, D. P., \& Marlowe, D. (1960). A new scale of social desirability independent of psychopathology. Journal of Consulting Psychology, 24, 349-354. https://doi.org/10.1037/h0047358

Damásio, B. F. (2012). Uso da análise fatorial exploratória em psicologia. Avaliação Psicologica, 11, 213-228. 
Dobriban, E., \& Owen, A. B. (2019). Deterministic parallel analysis: An improved method for selecting factors and principal components. Journal of the Royal Statistical Society: Series B (Statistical Methodology), 81, 163-183. https:// doi.org/10.1111/rssb.12301

Etchezahar, E., \& Imhoff, D. (2017). Relaciones entre el autoritarismo y la dominancia social de acuerdo al nivel de contraste ideológico del contexto socio-político argentino. Psicología, Conocimiento y Sociedad, 7, 59-75. http:// www.scielo.edu.uy/pdf/pcs/v7n1/1688-7026pcs-7-01-00059.pdf

Fleury, A. R. D., \& Torres, A. R. R. (2010). Homossexualidade e preconceito: o que pensam os futuros gestores de pessoas. Editora ABDR.

Freires, L. A. (2015). Atitudes frente à homoparentalidade: uma explicação a partir de variáveis explícitas e implícitas (tese de doutorado). Universidade Federal da Paraíba, João Pessoa. https://repositorio.ufpb.br/jspui/bitstream/tede/7521/2/arquivototal.pdf

Freires, L. A., Rezende, A. T., Loureto, G. D. L., Santos, W. S., Mendes, L. A. C., \& Gouveia, V. V. (2019). Escala multidimensional de preconceito sexual: propriedades psicométricas para o contexto brasileiro. Psicologia Ciência e Profissão, 39, 222-235. https://doi.org/10.1590/19823703003228490

Gato, J., \& Fontaine, A. M. (2016). Attitudes toward adoption by same-sex couples: Effects of gender of the participant, sexual orientation of the couple, and gender of the child. Journal of LGBT Family Studies, 12, 46-67. https://doi. org/10.1080/1550428X.2015.1049771

Giger, J. C., Orgambídez-Ramos, A., Gonçalves, G., Santos, J., \& Gomes, A. (2015). Evidências métricas da adaptação da Escala de Dominância Social numa amostra portuguesa. Avaliação Psicológica, 14, 143-151. https://doi.org/10.15689/ ap.2015.1401.16

Gouveia, V. V., Guerra, V. M., de Sousa, D. M. F., Santos, W. S., \& de Mesquita Costa, J.
(2009). Escala de Desejabilidade Social de Marlowe-Crowne: evidências de sua validade fatorial e consistência interna. Avaliação Psicológica, 8, 87-98. https://www.redalyc.org/ pdf $/ 3350 / 335027279008 . p d f$

Gusmão, S. E. É., da Silva Nascimento, B., Gouveia, V. V., Ferreira Filho, L. G., da Costa, K. M. R., de Moura, H. M., \& Monteiro, R. P. (2016). Valores humanos e atitudes homofóbicas flagrante e sutil. Psico-USF, 21, 367-380. https:// doi.org/10.1590/1413-82712016210213

Hooker, E. (1956). A preliminary analysis of group behavior of homosexuals. The Journal of Psychology, 42, 217-225. https://doi.org/10.1080 /00223980.1956.9713035

Henseler, J., Ringle, C. M., \& Sarstedt, M. (2015). A new criterion for assessing discriminant validity in variance-based structural equation modeling. Journal of the Academy of Marketing Sciences, 43, 115-135. https://doi. org/10.1007/s11747-014-0403-8

Herek, G. M. (2015). Beyond "homophobia": Thinking more clearly about stigma, prejudice, and sexual orientation. American Journal of Orthopsychiatry, 85, 29-37. https://doi.org/10.1037/ ort0000092

Kinsey, A. C., Pomeroy, W. B., \& Martin, C. E. (1948). Sexual Behavior in the Human Male. Saunders.

Lacerda, M., Pereira, C., \& Camino, L. (2002). Um estudo sobre as formas de preconceito contra homossexuais na perspectiva das representações sociais. Psicologia: Reflexão e Crítica, 15, 165 178. http://www.scielo.br/pdf/\%0D/prc/v15n1/ a18v15n1.pdf

Macedo, C. M. R. (2017). A "clínica pastoral” dos psicólogos cristãos no Brasil (dissertação de mestrado). Universidade do Estado do Rio de Janeiro.

Macedo, C. M. R., \& Sívori, H. F. (2018). Repatologizando a homossexualidade: a perspectiva de "psicólogos cristãos" brasileiros no século xxI. Estudos \& Pesquisas em Psicologia, 18, 1415-1436. https://www.e-publicacoes.uerj.br/ index.php/revispsi/article/view/42242 
Macedo, C. M. R. D., \& Sívori, H. F. (2019). The Sexual Diversity Debate in Brazilian Psychology: Professional Regulation at Stake. Psicologia: Ciência e Profissão, 39, 88-102. https://doi. org/10.1590/1982-3703003228496

Mesquita, D. T. (2018). Análise das concepções e práticas de psicólogas (os) frente às normativas do conselho federal de psicologia sobre diversidade sexual e de gênero (dissertação de mestrado). Universidade Federal de Juiz de Fora. http://hermes.cpd.ufjf.br:8080/jspui/bitstream/ufjf $/ 6821 / 1 /$ danieletrindademesquita.pdf

Pakula, B., Shoveller, J., Ratner, P. A., \& Carpiano, R. (2016). Prevalence and co-occurrence of heavy drinking and anxiety and mood disorders among gay, lesbian, bisexual, and heterosexual Canadians. American Journal of Public Health, 106, 1042-1048. https://doi.org/10.2105/ AJPH.2016.303083

Pachankis, J. E., Hatzenbuehler, M. L., Rendina, H. J., Safren, S. A., \& Parsons, J. T. (2015). LGB-affirmative cognitive-behavioral therapy for young adult gay and bisexual men: A randomized controlled trial of a transdiagnostic minority stress approach. Journal of Consulting and Clinical Psychology, 83, 875-889. https:// doi.org/10.1037/ccp0000037

Pacico, J. C. (2015). Como é feito um teste? Produção de itens. In C. S. Hutz, D. R. Bandeira \& C. M. Trentini (Eds.), Psicometria (pp. 55-70). Artmed.

Pasquali, L. (2003). Psicometria: Teoria dos testes na Psicologia e na Educação. Vozes.

Pasquali, L. (2010a). Instrumentação psicológica. Fundamentos e práticas. Artmed.

Pasquali, L. (2010b). Testes referentes a construto: teoria e modelo de construção. In L. Pasquali (Ed.), Instrumentação psicológica: Fundamentos e práticas (pp. 165-198). Artmed.

Pasquali, L. (2012). Análise fatorial para pesquisadores. LabPAM.

Pereira, A. D. S. L. S., Dia, S. M. P. D. S., Lima, T. J. S. D., \& Souza, L. E. C. D. (2017). As crenças sobre a homossexualidade e o preconceito contra homossexuais no ambiente de trabalho. Temas em Psicologia, 25, 563-575. https://doi.org/10.9788/ TP2017.2-10

Pereira, A. S. L. S., Alfaia, A. J. B., Souza, L. E. C., \& Lima, T. J. S. (2014). Preconceito contra homossexuais no contexto do futebol. Psicologia \& Sociedade, 26, 737-745. https://doi. org/10.1590/S0102-71822014000300022

Pereira, A., Monteiro, M. B., \& Camino, L. (2009). Estudo da validação das escalas de crenças sobre a natureza da homossexualidade e de preconceito contra homossexuais. Laboratório de Psicologia, 7, 21-32. https://doi.org/10.14417/ lp.683

Pereira, A., Pereira, C. R., \& Monteiro, M. B. (2016). Normative pressure to reduce prejudice against homosexuals: The buffering role of beliefs about the nature of homosexuality. Personality and Individual Differences, 96, 88-99. https://doi. org/10.1016/j.paid.2016.02.042

Pereira, C. R., Torres, A. R. R., Falcão, L., \& Pereira, A. S. (2013). O papel de representações sociais sobre a natureza da homossexualidade na oposição ao casamento civil e à adoção por famílias homoafetivas. Psicologia: Teoria e Pesquisa, 29, 79-89. http://bibliobase.sermais. pt:8008/BiblioNET/Upload/PDF4/003808.pdf

Pereira, D. F. (2017). Homossexualidade em cena: da naturalidade ao preconceito revisitando a produção científica nacional. Itinerarius $R e$ flectionis, 13, 01-19. https://doi.org/10.5216/ rir.v13i2.41309

Quintão, G. F. (2017). A nova direita cristã: alianças, estratégias e transfiguração do discurso religioso em torno do projeto de cura gay. Estudos de Sociologia, 22, 53-72. https://periodicos.fclar. unesp.br/estudos/article/view/9431/6783

Reppold, C. T., Gurgel, L. G., \& Hutz, C. S. (2014). O processo de construção de escalas psicométricas. Avaliação Psicológica, 13, 307-310. http:// pepsic.bvsalud.org/pdf/avp/v13n2/v13n2a18.pdf Rokeach, M. (1973). The nature of human values. Free Press. 
Smith, G., Bartlett, A., \& King, M. (2004). Treatments of homosexuality in Britain since the 1950s — an oral history: The experience of patients. $B M J, 328,1-3$. https://doi.org/10.1136/ bmj.328.427.37984.442419.EE

Smith, B. C., Armelie, A. P., Boarts, J. M., Brazil, M., \& Delahanty, D. L. (2016). PTSD, depression, and substance use in relation to suicidality risk among traumatized minority lesbian, gay, and bisexual youth. Archives of Suicide Research, 20, 80-93. https://doi.org/10.1080/13811118. 2015.1004484

Soares, A. K. S., Lopes, G. S., Rezende, A. T., Ribeiro, M. G. C., Dos Santos, W. S., \& Gouveia, V. V. (2016). Escala de Deseabilidad Social Infantil (EDSI): evidencias de validez factorial y fiabilidad. Avances en Psicología Latinoamericana, 34, 383-394. https://doi.org/10.12804/ apl34.2.2016.11

Sousa, F. H. F. (2017). A cura gay: uma decisão judicial que afronta os direitos humanos no Brasil?. Revista Eletrônica de Direito da Faculdade Estácio do Pará, 4, 1-18. http://www.revistasfap.com/ ojs3/index.php/direito/article/view/141
Sposito, S. E. (2015). Homossexualidades nas pesquisas em pós-graduação em psicologia: da despatologização à luta por direitos (tese de doutorado). Universidade Estadual Paulista. https://repositorio.unesp.br/bitstream/handle/11449/136106/000856237.pdf?sequen$\mathrm{ce}=1 \&$ isAllowed $=\mathrm{y}$

Toro-Alfonso, J. (2005). Estudio de las homosexualidades: revisión, retos éticos y metodológicos. Revista de Ciencias Sociales, 14, 78-97. https:// doi.org/10.4067/S0718-48082012000200007

Valentini, F., \& Damásio, B. F. (2016). Variância média extraída e confiabilidade composta: indicadores de precisão. Psicologia: Teoria e Pesquisa, 32, 1-7.https://doi.org/10.1590/0102$3772 \mathrm{e} 322225$

Viladrich, C., Angulo-Brunet, A., \& Doval, E. (2017). A journey around alpha and omega to estimate internal consistency reliability. Annals of Psychology, 33, 755-782. https://doi.org/10.6018/ analesps.33.3.268401

Whitley Jr., B. E., \& Kite, M. E. (2016). Psychology of prejudice and discrimination. Routledge. 